\title{
Perancangan Jaringan WLAN di PT. Gemopia Jewellery Indonesia
}

\author{
Septian Rheno Widianto, Yoyok Sabar Waluyo \\ Prodi Teknik Informatika \\ Jurusan Teknik Informatika dan Komputer \\ Politeknik Negeri Jakarta \\ Jalan Prof. G. A. Siwabessy, Kampus UI, Depok \\ septian.rheno@yahoo.de, yoyok.sw@tik.pnj.ac.id
}

Diterima: 16 September 2015. Disetujui: 17 Oktober 2015. Dipublikasikan: November 2015

\begin{abstract}
Abstrak - PT. Gemopia Jewellery Indonesia merupakan cabang yang terletak di Sukoharjo Jawa Tengah dan pusatnya berada di Korea. PT. Gemopia Jewellery Indonesia merupakan cabang yang keempat, diantaranya: China, Jepang dan Vietnam. PT. Gemopia Jewellery Indonesia didirikan di Indonesia pada tahun 2012, terdiri dari beberapa divisi yaitu: Ekspor \& Impor, Accounting \& Keuangan, HRD, CAD, WAX, Administrasi, Produksi dan IT. PT. Gemopia Jewellery Indonesia belum memiliki jaringan wireless LAN (Local Area Network), sehingga pegawai pada setiap divisi tersebut belum saling terkoneksi antar bagiannya, sehingga tidak fleksibel dan mengganggu mobilitas mau pun kenyamanan dari pegawai di setiap divisi. Tujuan membuat rancangan jaringan wireless LAN adalah solusi untuk menyelesaikan masalah mengenai jaringan komputer yang ada di PT. Gemopia Jewellery Indonesia. Metode yang digunakan adalah metode Waterfall. Tahapan dengan pendekatan metode Waterfall terdiri dari analisis, desain sistem, implementasi, testing, dan perawatan sistem. Hasil perancangan jaringan wireless LAN di PT. Gemopia Jewellery Indonesia yang tersusun dengan sistematis untuk membantu kinerja anggota dinas tersebut agar lebih efektif dan efisien.
\end{abstract}

Kata Kunci: perancangan jaringan, wireless LAN, waterfall.

\section{PENDAHULUAN}

Information and Communication Technology atau yang lebih dikenal dengan sebutan dunia IT memang tidak dapat dipisahkan dengan kabel.

Dunia IT yang erat hubungannya dengan dunia elektronik, menggantungkan kelancaran konekfitasnya pada dunia kabel. Didukung dengan perkembangan dunia jaringan komputer, semua komputer diharapkan dapat berkomunikasi satu dengan. Seorang user dapat mengakses internet di posisi mana pun selama masih berada dalam jangkauan sinyal wireless yang lain dengan medium tertentu [1].
Perkembangan jaringan komputer terus mengarah kepada penggunaan teknologi tanpa kabel atau wireless. Teknologi ini sudah merupakan standar yang digunakan dalam dunia teknologi informasi [2].

Berbagai peralatan genggam dilengkapi Infrared, Bluetooth, maupun WiFi yang digunakan secara wireless. Dalam teknologi jaringan komputer sendiripun teknologi wireless ini sering disebut dengan Wireless LAN. Teknologi wireless menawarkan beragam kemudahan, kebebasan, mobilitas dan fleksibilitas yang tinggi [3]. Teknologi wireless memiliki kelebihan dibandingkan teknologi kabel yang sudah ada. Teknologi wireless sangat nyaman untuk digunakan. Seorang user dapat mengakses internet di posisi mana pun selama masih berada dalam jangkauan sinyal wireless [4].

Kemudahan-kemudahan yang ditawarkan teknologi wireless menjadi daya tarik tersendiri bagi para pengguna komputer menggunakan teknologi ini untuk mengakses suatu jaringan komputer atau internet [5]. Beberapa tahun terakhir ini pengguna wireless mengalami peningkatan yang pesat. Peningkatan pengguna ini juga dibarengi dengan peningkatan jumlah hotspot yang dipasang oleh ISP (Internet Service Provider) di tempat-tempat umum, seperti kafe, mal, atau bandara, kantor maupun kampus telah menyediakan fasilitas hotspot gratis [6].

PT. Gemopia Jewellery Indonesia selama ini belum memiliki jaringan wireless LAN (Local Area Network). Sehingga pegawai di perusahaan tersebut belum saling terkoneksi antar divisi. Sehingga hal ini tidak fleksibel dan mengganggu mobilitas mau pun kenyamanan dari pegawai tersebut [7]. 


\section{METODE PENELITIAN}

\section{A. Metode Pengumpulan Data}

Adapun metode yang digunakan penulis untuk mengumpulkan data-data adalah sebagai berikut :

a. Wawancara (Interview)

Wawancara adalah metode pengumpulan data dengan cara dialog langsung atau mengajukan pertanyaan langsung kepada narasumber mengenai segala sesuatu yang berhubungan dengan masalah yang diteliti. Metode ini dilakukan dengan cara tanya jawab langsung atau dengan email [8].

b. Observasi

Metode pengumpulan data dengan melakukan pengamatan secara langsung dan pencatatan mengenai bagaimana proses kerja pada PT. Gemopia Jewellery Indonesia.

c. Studi Pustaka

Cara pengumpulan data dengan mengumpulkan dan mempelajari dokumendokumen, buku-buku dan media referensi lainnya yang berhubungan dengan masalah penelitian

\section{B. Metode Analisis}

Proses pengembangan sistem yang dipakai adalah Waterfall. Model pendekatan ini dilakukan secara rinci dan direncanakan. Tahapan yang dilakukan dalam pendekatan Waterfall sebagai berikut:

\section{Analisis}

Pada tahap ini, penulis bertemu dengan pihak PT. Gemopia Jewellery identifikasi keseluruhan sasaran pengembangan studi kelayakan dan studi terhadap kebutuhan atau yang diperlukan PT. Gemopia Jewellery yang meliputi model interface, teknik prosedural maupun teknologi yang akan digunakan.

\section{Design Sistem}

Pada tahap kedua ini, penulis bekerja sama dengan PT. Gemopia Jewellery untuk memprogram, merancang atau mendesain mengembangkan untuk pemodelan sistem yang akan dibuat.

\section{Implementasi}

Tahapan selanjutnya setelah sistem selesai dirancang selanjutnya adalah menerapkan ke dalam program. Dalam hal ini yang dimaksud dengan pembuatan sistem adalah pembuatan kode program. Pemrograman merupakan kegiatan menulis kode program yang akan dieksekusi komputer. Kode program yang ditulis berdasarkan dokumentasi yang disediakan oleh pengamatan secara langsung da pencatatan rinci. Hasil program yang sesuai dengan desainnya akan menghasilkan program yang sesuai dengan yang dibutuhkan pemakai sistem.

\section{Testing}

Pengujian dilakukan untuk memastikan rancangan yang dibuat telah sesuai dengan desainnya dan semua fungsi dapat dipergunakan tanpa ada kesalahan. Dalam tahap pengujian sistem ini adalah proses menerapkan hasil program ke dalam dunia nyata. Tahapan testing bertujuan untuk menerapkan sistem instalasi jaringan komputer nirkabel untuk kegiatan mengakses data.

\section{Perawatan Sistem}

Tahapan selanjutnya sistem dapat diselesaikan adalah perawatan bertujuan agar sistem dapat berjalan optimal dan data dapat tersimpan dengan aman. Tahapan yang perlu dilakukan untuk merawat sistem adalah :

1) Backup Data

Backup data dilakukan secara periodik dalam selang waktu tertentu untuk menjaga keamanan data yang tersimpan dalam memori komputer.

2) Packing Data

Packing data dilakukan untuk menghapus datadata yang sudah tidak diperlukan atau dipakai lagi sehingga dapat menghemat memori komputer.

\section{HASIL DAN PEMBAHASAN}

\section{A. Analisis dan Pembahasan}

Analisis sistem, perancangan, dan pengembangan sangat dibutuhkan yaitu untuk menganalisis sistem dengan mempelajari masalahmasalah yang timbul dan menentukan kebutuhankebutuhan pemakaian sistem untuk mengidentifikasi pemecahan yang beralasan.

Analisis sistem dapat difungsikan sebagai penguraian dari suatu informasi yang utuh kedalam bagian-bagian komponennya dengan maksud untuk mengidentifikasi dan menganalisis permasalahanpermasalahan yang diharapkan sehingga dapat diusulkan perbaikannya.

\section{B. Desain Sistem}

Desain sistem topologi yang akan digunakan dapat bertahan dalam jangka waktu yang lama dan dapat mengikuti perkembangan teknologi. Dari pengamatan dan hasil survey di lapangan mengingat perkembangan dari PT. Gemopia Jewellery Indonesia, dari luas bangunan hingga jumlah karyawan di setiap divisi, maka diputuskan untuk menggunakan topologi star.

\section{1) Desain Jaringan Komputer}

Berikut ini adalah model jaringan yang akan dibuat di PT. Gemopia Jewellery Indonesia. Model jaringan ini dibagi menjadi 8 divisi yaitu HRD, Ekspor \& Impor, IT, Accounting dan Keuangan, CAD, WAX, dan ADM. Masing-masing desain ditunjukkan pada Gambar 1-7. 

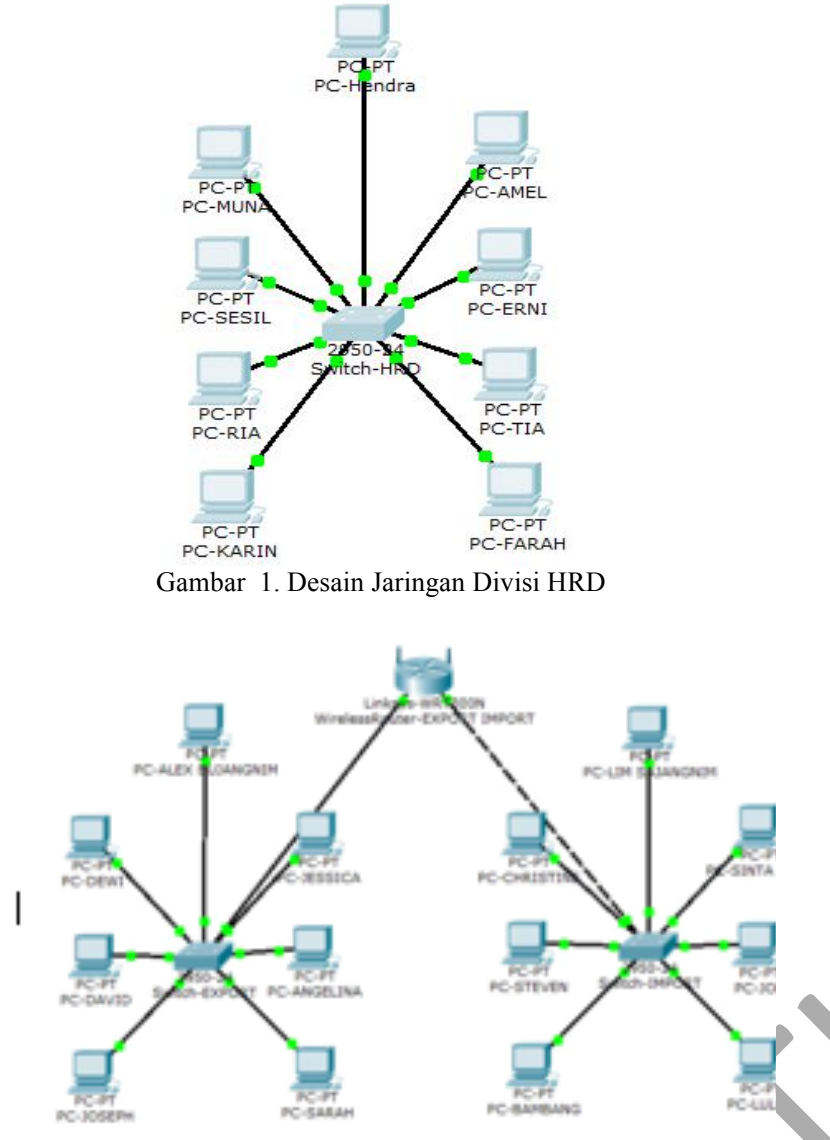

Gambar 2. Desain Jaringan Divisi Ekspor \& Impor

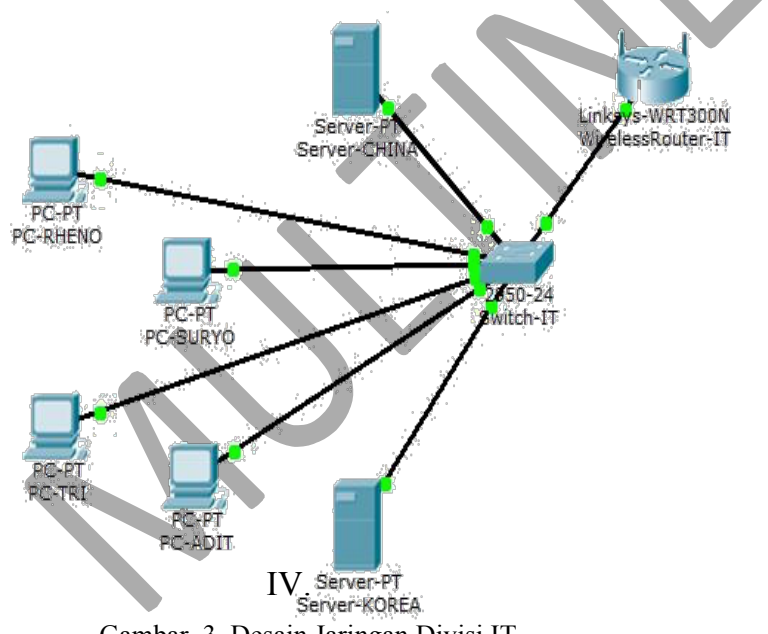

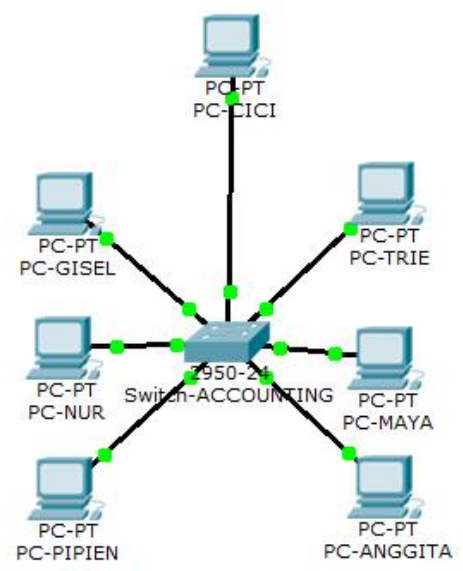

Gambar 4. Desain Jaringan Divisi Accounting \& Keuangan

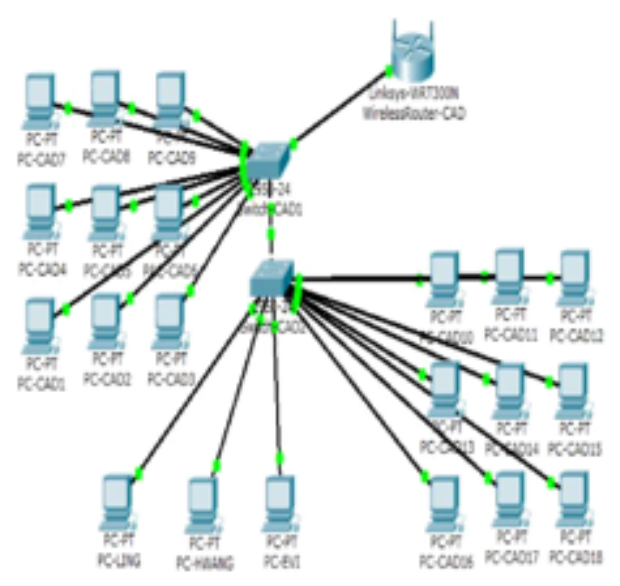

Gambar 5. Desain Jaringan Divisi CAD

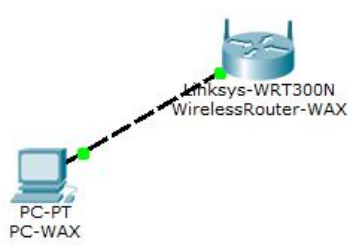

Gambar 6. Desain Jaringan Divisi WAX

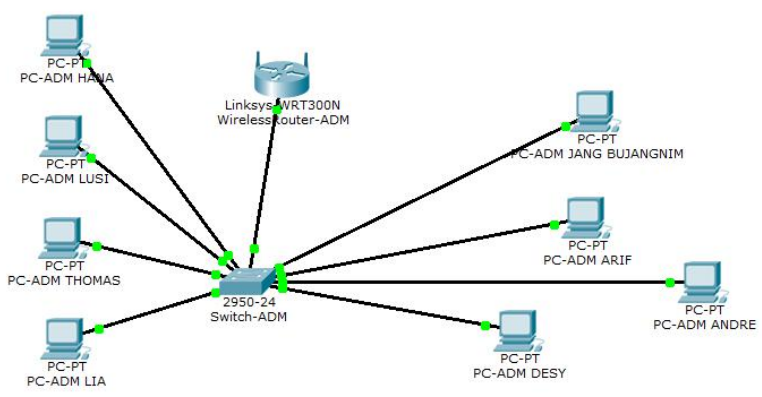

Gambar 7. Desain Jaringan Divisi ADM 


\section{Implementasi Sistem}

Tahapan setelah desain jaringan selesai dibuat adalah menerapkan ke dalam program. Dalam hal ini yang dimaksud dengan pembuatan sistem adalah pembuatan program yang berbentuk setting IP dan tabel routing.

\section{Testing Sistem}

Tahapan setelah proses konfigurasi selesai dilakukan adalah tahapan pengujian koneksi jaringan apakah sudah berhasil terkoneksi dengan cara ketik ping[spasi]IP address tujuan pada jendela Command Prompt. Apabila setelah melakukan ping ada tulisan Reply from, maka jaringan telah berhasil terkoneksi dan jika tulisan lost maka jaringan belum berhasil terkoneksi.

\section{Maintenance Sistem}

1. Melakukan perawatan atau maintenance terhadap software dan hardware yang tersedia.

2. Melakukan proses backup file bertujuan untuk mengurangi resiko dari rusaknya aplikasi atau hilangnya database yang ada, serta menjaga kelancaran kinerja dari jaringan.

\section{KESIMPULAN DAN SARAN}

\section{A. Kesimpulan}

1. Jaringan baru yang didesain dan dirancang ini diharapkan dapat membantu menyelesaikan pekerjaan dengan baik dan meningkatkan efisiensi kerja.

2. Penerapan jaringan yang ini juga dapat memberikan informasi serta pengolahan data yang akurat.

3. Keamanan Jaringan Wireless LAN sangat terjamin keamanannya karena bersifat mandiri jika dibandingkan dengan jaringan MAN/WAN yang memiliki cakupan yang lebih luas.

\section{B. Saran}

Berdasarkan hasil penelitian yang dilakukan penulis di PT. Gemopia Jewellery Indonesia, maka penulis memberikan saran-saran sebagai berikut:

1. Perlu diadakan evaluasi terhadap jaringan yang digunakan untuk penyesuaian.

2. Perlu adanya tambahan dana dari PT. Gemopia Jewellery Indonesia untuk mengembangkan jaringan agar lebih maju.

\section{REFERENSI}

[1] Ekpenyong, M dan Joseph Isabona. 2010. Modeling Throughput Performance in 802.11 WLAN. Nigeria: Department of Computer Science University of Uyo Uyo.

[2] IEEE. 1999. Wireless LAN Medium Access Control (MAC) and Physical Layer (PHY) Specifications High-speed Physical Layer in the $5 \mathrm{GHz}$ Band. United States: IEEE.

[3] Froztheo. (2011). Pengertian Waterfall, Ponk's Daily, Bandung.

[4] Kim, Youngsoo. Throughput Enhancement of IEEE 802.11 WLAN via Frame Aggregation Seoul: Samsung Advanced Institute of Technology

[5] Mahmoud, A S. Network Simulation Tools - OPNET Modeler (Wi-Fi Network Implementation).: Computer Engineering Department King Fahd University of Petroleum and Minerals.

[6] Prokkola, J. 2006. Simulations and Tools for Telecommunications 521365S: OPNET Network Simulator. Finland: VTT Technical Research Centre of Finland.

[7] Singh, J. 2009. Quality of Service in Wireless LAN Using OPNET MODELER. Patiala: Computer Science and Engineering Department Thapar University.

[8] Walke, B H.2002. Mobile Radio Networks (Networking, Protocols and Traffic Performance). England: John Wiley $\&$ Sons, Ltd. 